\title{
Composing a Further Life: Introduction to the Special Issue
}

Part of the challenge ... in growing older, is to discover the ways, arising from a lifetime of experience and in spite of reduced strength and stamina, in which it continues to be possible to contribute. The corresponding challenge to society is to recognize that contribution and to benefit from it instead of dismissing it.

-Mary Catherine Bateson, Composing a Further Life

Theorists have to expand their imaginations to encompass all the situations where the key axis of difference is the one never mentioned-being aged by culture.

-Margaret Morganroth Gullette, Aged by Culture (105)

Three years ago, it was estimated that $8.5 \%$ of the world's population was aged sixty-five and older; by 2030, that number is expected to increase to $12 \%$; by 2050, $16.7 \%$-all while the population of people age twenty and under remains relatively flat. Soon, the world is expected to reach a demographic milestone, as people who are sixty-five and older will, for the first time in history, outnumber children under age five (He, Goodkind, and Kowal 3). The United States, home to the post-World War II baby boom, is in the midst of its own major demographic shift, as the population of people age sixty-five and over will have more than doubled in the first third of the twenty-first century, constituting almost $21 \%$ of the US population by 2030 (Federal Interagency 2). With changes to fertility rates, poverty levels, and access to health care, global aging "is poised to become one of the most significant social transformations of the twenty-first century" (United Nations 1). But what is the significance of this social transformation? To world leaders and global organizations, the exigence of global aging is largely economic-and largely one of crisis. More often than not, public response to aging demographics is framed as a dangerous balancing act, wherein policymakers must choose between addressing the needs of different generations; as one assessment report phrases it, nations must prepare "to provide a decent standard of living for the old without imposing a crushing burden on the young" (Jackson, Peter, and Howe iii). However, as this special issue of Literacy in Composition Studies illustrates, there are many other ways-cultural, ideological, rhetorical, and pedagogical, among others-in which aging might matter now more than ever.

The story of growing old in this transitional moment is "ill told with statistics" (Bateson, Composing a Further Life 23). For Mary Catherine Bateson, human lives are composed: a blend of conscious arrangement and improvised creativity. As the lifespan of people in many parts of the world extends and as a fourgeneration society becomes increasingly commonplace, the meanings of life and its stages must also expand and be composed anew. In referencing Bateson's metaphor of composing in the title of this special issue, Suzy and I aimed to draw attention to the relationships among aging, literacy, and composition in two ways. The first and perhaps most obvious is that, in assembling this special issue, the intention was to gather and inspire studies of literacy and composition from the perspective of an entire lifespan, including old age. Second, but no less important, Bateson's use of composing signals a particular attention to old age and aging as something more than discrete demographic categories or predictable biological processes: old age is, itself, composed-by cultures, by social norms, by interpersonal relationships, by institutions, 
and by representations of the self. In sharing the work included in this special issue, Suzy and I hope to exemplify the importance of including later life in the literacy and composition research agenda, and urge literacy and composition scholars to consider how literate activity shapes, and is shaped by, ideologies of aging.

In 1999, Gail Weinstein and Simone LaCoss observed that information about literacy and its functions, circumstances, and values among older people was "virtually nonexistent" (Weinstein and LaCoss 318). Now, nearly twenty years later, the vast majority of studies of composition and literacy continue to emphasize the literacy learning and practices of younger people. The few studies of literacy and older people, specifically, remain siloed in fields (e.g., educational gerontology) that have, as yet, little cross-talk with literacy and composition studies. This special issue marks an effort to focus and foster the nascent interest in aging within literacy and composition research.

Of course, composition and literacy research has not been totally silent about aging. Given that literate activity is complex, dispersed, and entangled with many interconnecting systems, literacy learning and practice remains relevant to human experience well past adolescence and early adulthood. It is no accident, then, that older people occasionally feature as central figures in research on writing, composition, and literacy. Although composition studies, as represented by research published in journals such as College Composition and Communication, Composition Forum, and Composition Studies, remains a field primarily attuned to the development of young adult writers in postsecondary settings, a few researchers have turned their attentions to the experiences and development of "adult students" (see, for example, Cleary, "Anxiety and the Newly Returned Adult Student"; Cleary, "Flowing and Freestyling"; Connors; Crow, "What's Age Got to Do with It?"). Although still sometimes known as "non-traditional students," adult college students older than twenty-four have, in fact, comprised approximately $40 \%$ of the US college student population since at least 2000 (National Center for Education Statistics). Studies of adult student writers present a rare but invaluable opportunity to consider an often-overlooked question for the field: What difference does age make for writing and literacy? Yet the broad definition of adult student as "older than twenty-four" presents an enormous age range in which to consider age as a meaningful identity category, and thereby collapses what may be important distinctions for writing development that are lost when age, itself, is left unexamined.

Meanwhile, within literacy studies, the inclusion of older adults is more commonplace. Widely influential literacy research has, for instance, documented the cross-generational ebbs and flows of literacy during periods of cultural, social, and economic change (e.g., Brandt, Literacy in American Lives; Brandt, The Rise of Writing; Selfe and Hawisher; Heath), in which older adults figure most often as literacy sponsors and mentors for younger generations, or else as points on a timeline, marking historical shifts in literacy. Such cross-generational comparison is essential to understanding the larger social, cultural, and economic contexts of literacy-a value to which I'll return later in this introduction. However, just like composition studies, in the vast majority of studies of literacy, including many of those examining older adults' learning and literacy practices, age remains an "absent presence." Just as Catherine Prendergast must "exert a little extra effort" to track the role of race in writing studies research, in which racial difference is present but too-rarely analyzed (36), here, in regard to aging, we might make a similar observation. Age and ageism are ubiquitous in our classrooms, our research sites, and our own bodies, while remaining 
largely absent from overt analysis.

In introducing this special issue, I begin with a brief overview of scholarship in the interdisciplinary field of age studies in order to spark further scholarship on aging at the nexus of literacy and composition studies. As the remainder of this introduction and the contents of this entire issue demonstrate, the inclusion of age analysis in writing studies enacts the very mission of LiCS: to bridge scholarship in literacy and composition. For composition studies, attention to aging (particularly during old age) necessitates stepping further away from the "pedagogical imperative" of composition studies, toward a disciplinary commitment to the broader study of writers and writing (Dobrin). For literacy studies, it means examining an ideological dimension of literacy that has, thus far, been largely ignored. Unlike the bulk of geriatric medicine and much of gerontological research, age studies unites disciplines around the study of ideologies of aging. Through the project of age studies, researchers positioned at the intersection of composition and literacy studies may find a critical framework through which, as Bateson urges, to recognize the contribution older people might make to our own disciplinary knowledge, and to "benefit from it instead of dismissing it" (Composing a Further Life 18). The characterization of age studies I offer here aims to contextualize this special issue's central claim: that aging is a crucial dimension of analysis to which literacy and composition studies are well positioned to contribute.

\section{Age Studies}

Age studies emerged from feminist philosophy, as Simone de Beauvoir's La Vieillesse (or "Old Age," a title euphemistically translated for anglophone readers as Coming of Age) is often reclaimed as the field's germinal text. ${ }^{1}$ Originally published in 1970, Beauvoir's book presented what would years later become the unifying principle of the age studies project: that "old age can only be understood as a whole: it is not solely a biological, but also a cultural fact" (Beauvoir 13). The term age studies was first introduced in 1993 by Margaret Morganroth Gullette, a feminist cultural critic who used the term to capture "a large interdisciplinary zone" in which scholars were increasingly interested in the critical analysis of age-related issues ("Creativity" 45). Among age studies scholars and activists, age is more than a minor variable; it is a dynamic identity category alongside gender, race/ethnicity, class, sexual orientation, and ability. Age studies scholarship centrally involves critical investigations of "being aged-by-culture" (Gullette, "Age Studies and Gender"; Gullette, Aged by Culture)—work that is distributed across literature, history, media studies, sociology, psychology, anthropology, and other fields.

As a cultural fact, age is not neutral; rather, age has situated meanings. As a demonstration, consider the contrasting meanings associated with old age at various historical periods. In Western Europe during the seventeenth century, the cultural meanings of old age were heavily influenced by both Christianity and early medicine-often to contradictory effects. Scriptural commands to "honour the face of the old man, and fear thy God" (Lev. 19:32, qtd. in Botelho 122), as well as commandments to "honor thy father and mother," were shared across the deeply divided Catholic and Protestant communities, such that old age was seen as a spiritual ideal-even if, in reality, older people (especially women and the poor) were not always treated accordingly. At the same time, seventeenth-century medicine cast old age as a period in which individuals were "drying up and wasting away physically while at the same time manifesting a 
melancholic and phlegmatic temperament" (Botelho 127 ). Thus, it became a goal of seventeenth-century medicine to prolong youth and prevent aging - a goal of Western medical practice that lingers still. Despite religious attachments to old age as symbolic of an exalted spiritual ideal, medical knowledge framed old age foremost as a problem.

By the mid-twentieth century, a new set of contradictory cultural meanings for old age had emerged in many European and North American cultures in response to industrialization and technological development. Medical advancements, including the rise of joint replacement and physical therapy, and the wider adoption of state pensions and retirement policies created a new era in which many people were living longer and healthier lives, but leaving the workforce earlier than ever before-often by mandate (Thane 277 ). In response, US political discourse of the late twentieth century saw the rise of the "greedy geezer" stereotype. In this enduring cultural catch-22, older adults are deemed unfit for the labor market and thus discouraged from earning wages, but as pension collectors and frequent users of health care systems, they become national burdens. The expression "greedy geezer" was first popularized through the cover art and feature article of a 1988 issue of The New Republic, in which Henry Fairlie characterized older Americans as "coddled" drains on national resources: "All the way from the Pacific to the Atlantic," Fairlie rages, "you can see the old lined up in banks, feeding into their accounts the checks from a range of federal agencies," as well as rising numbers of "pampered ones" who are "riding around in golf carts ... instead of taking an invigorating walk" (21). Geriatrician and proto-age studies scholar Robert Butler-who is credited with coining the term ageism-challenged Fairlie's essay as a form of political scapegoating. In addition to falsely representing older people's share of social benefits from taxpayers, Butler contends, such accusations "foment an artificially manufactured intergenerational war" (1372). Greedy geezer indictments are not, however, unique to right-wing argument. In the present cultural climate, members of the Baby Boomer generation-US-born citizens currently between ages 52 and 70, according to Pew Research Center definitions-have been condemned en masse from the political left for bankrupting the financial, social, and environmental future of upcoming generations (see, for example, Gibney; Tankersley). ${ }^{2}$

In contrast to the "greedy geezer" sentiments in the US, the role of filial piety-respect for elders as a virtue in Confucian philosophy-has been central to understanding intergenerational relationships and attitudes toward aging in East Asia. However, while a cultural value of filial piety may be still be embedded within institutional structures-for example, in some East Asian languages, via the use of age-based honorifics - social changes may be gradually weakening filial piety. Studies suggest, for instance, that the shift from an agrarian to an urban economy in China has led many adult children to seek residence and employment in cities geographically distant from their parents; in such cases, filial piety, in the form of financial support, is reduced (Cheung and Kwan). As these various examples illustrate, different cultures embed different meanings and ideologies of old age within institutions (legislation, medical practice, language), thus creating a particular cultural habitus of aging. Yet no culture or historical period contains static or singular meanings of old age. Examining age for its cultural meaning renders age less fact than paradox, as "chronological age is both meaningful and meaningless", and as aging is "both within our control and beyond our control" (Cruikshank 207-208).

But if old age and aging are culturally determined categories, then old age is also learned. Much in the 
same way that we become acculturated to gender roles, age studies scholars recognize that we learn how to talk to and about old people, how to see and not see them, and how be old through discourses circulating cultural scripts-through a "curriculum of aging" (Bowen, "Beyond Repair") - that circulate and replicate "the din of representations, unseen internalizations, unthinking practices, [and] economic structures of dominance and subordination" (Gullette, Aged by Culture 27). Circulation of stereotypes-that older people are ugly, inflexible, incapable - and the use of dehumanizing terms that reduce older people to body parts (blue-hairs), to familial roles (grandma), or to clinical problems (geriatrics) are common ways we are acculturated to think about aging-and, specifically, to fear and be reviled by it. Another way is in how aging figures in grand narratives of culture. Age studies historian Thomas R. Cole noted that Medieval iconography suggests a vision of aging as a "womb to tomb" circle; this conceptualization was eventually displaced by the "rising and descending staircase" of the seventeenth century (4-5) - a shift that would, perhaps, mark the origins of what Gullette would later critique as the dominant decline narrative of aging (Declining; Aged by Culture). Silence and absence, too, contribute to repeating loops within the curriculum of aging, as the very absence of varied models of older people can leave us dependent on limiting grand narratives of aging as our only guides.

If aging is partly learned, age studies provides some hope for the possibility of un-learning: of changing cultural scripts that are "thwarting our development" as we age (Cruikshank 22). As individuals, we may develop critical awareness of how cultural values may be detrimental to self-esteem as we become middle-aged and older, and become conscious and critical of age ideologies. Margaret Gullette describes this critical lens-the sort developed through the work of age studies scholars and activists-as age theory (Declining 68). By being in possession of critical age theory, individuals can be aware of pervasive cultural values and myths that restrict their abilities to age with self-esteem and dignity-a necessary step to recognize, resist, and revise cultural scripts of aging. Age theory could do more, though, than provide individual fortitude against the onslaught of the "hostile age gaze" (Gullette, Declining 68) as it impacts self-esteem in old age. Put to its broadest use, age theory can provide incentives and frameworks for revising anti-aging cultural scripts-including those that discourage literacy learning and practice, as well as those that echo, mostly unnoticed, in the pages of our journals, in conference hallways, and in our own classrooms. For this reason, age studies scholars have advocated for a pedagogical approach to improving intergenerational relationships and age-awareness. "Teaching aging studies or age studies concepts," writes Leni Marshall, "makes a difference in students' self-perceptions and actions related to their own aging processes, in their understanding of and interactions with elders, in their comprehension of the social and economic cultural structures that constrain people's experiences of aging and old age, and in their workplace readiness" (56).

Writing studies and age studies, as I have elsewhere noted, "share an interest in recovering the previously ignored work of marginalized social groups in order to make sense of the rhetorical worlds in which they write or otherwise make meaning; both turn a critical eye on the ideologies that create and sustain systems of oppression through discourse; and both identify opportunities for the resistance to, appropriation of, or confirmation of dominant ideologies through literate acts" (Bowen, "Literacy Narrative"). Whether through pedagogical, theoretical, critical, or methodological connections, writing studies and age studies have much to learn from one another. 


\section{Older People in Literacy and Composition Studies}

Despite its sparseness, the inclusion of older people has already enriched literacy and composition studies, drawing attention to aspects of composing and literate activity that are often less salient in the experiences of younger people. As a reminder of the work already circulating within our fields, beckoning for closer examination of age and its meanings, I offer several thematic clusters of work in literacy and composition studies that begin to reveal the value of studying the literacy learning and practices of older people-many of which suggest important ways that literacy and composition studies might contribute to the critical project of age studies.

\section{Literacy Learning Across the Lifespan: The Role of Role}

While many studies of younger people acknowledge that literate activity, even in the context of school, is always multi-motivational (Prior and Shipka 206), studies of older people yield rich information about literacy learning and practice that is usually distanced from the contexts and motives of schooling. In this regard, studies of literacy among older people have been essential to exploring the lasting impact of social roles on literate activity. As Deborah Brandt notes in a discussion of roles in workplace writing, "While often congruent with certain stages of life (i.e., youth, middle age, old age) the multiple and simultaneous roles most people play in families, communities, and workplaces condition developmental trajectories and possibilities even as they interact with one another" ("Writing Development" 251 ). Studies of later stages of life afford researchers a means of tracing the trajectories of development and motives for literacy learning and practice as individuals use literacies to shed, embrace, resist, or maintain both new and familiar social roles. In particular, as more people live longer and more active lives, literacy is particularly important for shaping what Mary Catherine Bateson calls "Adulthood II." Commonly occurring after child-rearing and career-building efforts have subsided but before the biological effects of aging place greater constraints on productivity or quality of life, Adulthood II begins "[w]hen you realize that you have done a lot of what you hoped to do in life but that it is not too late to do something more or different" (“In Search" 52).

As many studies have begun to show, literate activity is one significant resource for establishing and maintaining social roles through Adulthood II and into old age. For example, Harry, a sixty-six-year-old retired Royal Navy veteran featured in David Barton and Mary Hamilton's Local Literacies, engages in many routine literacy practices, despite having no formal education after leaving school at fourteen. By meeting with a friend every Wednesday to read and discuss local news and write letters to the newspaper, helping his grandchildren with their homework, reading countless "authentic [nonfiction] war books," and occasionally writing about his Navy experience during World War II, Harry continues to seek out and inhabit meaningful social roles in his community, in his family, and in his country (81 -83). Similarly, John Branscum's interpretation of the digital literacy narrative of sixty-five-year-old Frank Quickert reveals that Frank's affinity for immersive, exploration-centered video games affords him opportunities in his "semiretirement" to extend and explore familiar subject positions from his off-screen life:

In the semiotic domains Frank has occupied in both his real and gaming lives, he has stressed a macro-social sense of self where he is both player and an avatar of larger social forces: as God's 
shepherd in his role as priest, as the people's voice in his role as state representative, as an incarnation of the law in his role as director of law, and as part of a larger, transhistorical, economic leviathan in his role as investment advisor. (225)

In my own research, too, tracing the literate lives of older adults has lent itself to careful consideration of the "role of role." Beverly, at age eighty-one, used emergent and remediated print- and digital-based literacies-most of which were developed as part of her changing and gendered roles as secretary and later manager at a paper mill-in order to continue to assert agency and authority in her family-based social media literacy practices, despite her relatively novice status as a social media user ("Resisting"). As these cases only begin to illustrate, not only are literacy practices taken up in the context of particular social roles, those literacy practices can be called upon by individuals to sustain, reinvent, or reject social roles in later life-particularly at stages of life, such as Adulthood II and old age, when social roles aren't as clearly outlined as they are earlier stages.

\section{Cross-Generational Perspectives of Literacy}

At the time Deborah Brandt interviewed her for the research project that would become Literacy in American Lives, Martha Day was eighty-nine and "still stinging" from the preference her parents showed her brother, who was sent to college, while the equally talented Martha was not (32). Nonetheless, Day's agrarian upbringing in the rural Midwest became a resource-an example of what Brandt came to call "reservoir s of opportunity"-for literacy acquisition during a moment of economic change, which she leveraged into a career as a writer (Literacy in American Lives 34). As agrarian economies grew in the 1940s, so did the industry of farm magazines, which advertised farming equipment. When the local newspaper editor bought a small farm magazine, Day was primed to share press releases and bulletins, and occasionally to contribute to a women's interest column - a role that expanded once the small magazine was sold to a larger firm. After a full career as a writer, Day, at eightynine, "was still writing and finding her constituency," having published some recent work in "senior citizen magazines" (36). While remaining bound to the agrarian conservative culture was largely the result of gender discrimination, Day could leverage her agrarian values to secure work as a writer: a transition that "depended on being well connected to an older order on whose value she could continue to trade" (37). Brandt contrasts Day's success story with the story of Barbara Hunt, who-apart from being born in 1971, sixty-eight years after Day-shared a near-identical upbringing, as the daughter of a dairy-farming family in a small, conservative agrarian community. However, by the time Barbara was growing up, close-knit agrarian communities were no longer prevalent, and thus the values and knowledge she absorbed from her upbringing no longer enjoyed the same market value as Day had enjoyed before her retirement in 1968.

The contrasting retrospective accounts of two women, growing up in similar environments but at different historic moments, yields one of the most crucial findings of Brandt's work in Literacy in American Lives: that "literacy learning is conditioned by economic changes," which "devalue onceaccepted standards of literacy achievement but, more seriously, destabilize the social and cultural trade routes over which families and communities once learned to preserve and pass on literate know-how" (42). This finding has direct implications on composition classrooms and curricula, within and against national rhetorics of literacy achievement: 
The school's responsibility should not be merely_and perhaps not mainly_to keep raising standards, revising curricula, and multiplying skills to satisfy restless pursuers of human capital ... Economic changes create immediate needs for students to cope with gradual and sometimes dramatic alterations in systems of access and reward for literacy learning that operate beyond the classroom. (43-44)

To say that such important claims would have been impossible if Brandt had not included narratives of older people (the oldest participant was ninety-eight) among those of younger adults and children, would be an overstatement. Historiography, statistical research, and other methods are also effective in tracing literacy's ebbs and flows amid economic and social change. However, as Brandt's study exemplifies, these contrastive personal histories serve as crucial repositories of literacy's histories and ecologies: the historic, psychological, and social dimensions of literacy that arise, weave together, change, and vanish over time.

In addition to longitudinal, cross-generation studies represented in work by Brandt, Shirley Brice Heath, and Cynthia Selfe and Gail Hawisher (among others), studies have also demonstrated how the oldest members of a population can be crucial to the formation and maintenance of group identity. Studies of communal efforts by elders to preserve cultures and to establish legacies have contributed to expanding theories of literacy. For example, the widely influential concept of literacy sponsorship has been expanded through studies of the efforts of older people to reproduce literate legacies in future generations. Although not exclusive to the literacy practices of older people, Alanna Frost's study of First Nations women in British Columbia includes Mary John, a Saiek elder-so named for her community leadership and seniority, but whose politically motivated literacy stewardship practices began in earnest after age sixty. Through analysis of Mary John's long-term efforts to use literate activity to "work toward rhetorical sovereignty" (57) and "practice and protect traditional literacies that are threatened" (70), Frost builds from the concept of literacy sponsorship and outlines "literacy stewardship," a concept more precise to the work of people like Mary John. Also expanding the concept of literacy sponsorship, Charlotte Hogg's From the Garden Club: Rural Women Writing Community documents the literacies of older women in Paxton, Nebraska, who use literate activity to create a coherent sense of local community. As they "grounded themselves in space and time through their writing against everything moving around them and past them" (32), they illustrate a particular form of sponsorship that involves "producing and sharing culture and history for future generations" (132).

Multi-generational studies within single families have proven useful to conceptualizing the role of family, home, and intergenerational relationships in literacy learning and rhetorical education. Suzanne Rumsey's study of her own family's multimodal, home-based literacy practices yielded the concept of heritage literacy, which captures "how people transfer literacy knowledge from generation to generation and how certain practices, tools, and concepts are adapted, adopted, or alienated from use" ("Heritage Literacy" 575). The three generations of women in Rumsey's autoethnographic study made agentive decisions about how multimodal literacies and technologies "are accumulated across generations" (576). Many of these cultivated, accumulating heritage literacies become treasured practices, or what Jamie White-Farnham calls rhetorical heirlooms: "literacy practices acquired not through formal education, but through family knowledge" (210). Through such attention to the intergenerational relationships among grandparents, parents, and children, researchers capture important aspects of literacy and learning that 
are likely unavailable to studies that focus exclusively on a single (younger) generation of learners.

\section{Technological Change and Digital Literacy Development}

As collective attention to digital technologies in literacy learning reached new heights in the first decade of the new millennium, adults with decades of engrained and sometimes-well-rewarded experience with print-based, alphabetic literacies found themselves confronting a sudden tectonic shift that put new limits on their hard-won expertise. Debra Journet articulated her own sense of the moment of change, as a self-described senior faculty member:

I have begun to recognize that what I and my students consider "writing" are very different phenomena. Young people today move more fluently among words, sound, and image; they report experiences with technologies I only dimly understand; and they write in genres I have never heard of. Confronting this sea change-trying to understand what might be called the new work of composing-I am striving to reconsider how I define my core responsibilities as a teacher. (107-108)

This technological "sea change" prompted Journet to explore and to experiment, despite her "novice status" with technology - the demand to learn made more pressing, in her view, "because senior colleagues represent powerful allies in efforts not just to use but also to advocate for technology" (108 , original emphasis). That Journet shares her story at all, despite "never [having] written anything for publication that depends so heavily on personal experience" (119), marks a significant moment at which many older faculty members had begun to wonder, as Angela Crow overheard one fiftysomething-year-old colleague ask, "Why do I feel like a basic writer?" (Aging Literacies 20).

In part responding to concerns that began growing among many "senior" writing faculty, Angela Crow's Aging Literacies focuses specifically on the challenges that emerging literacy technologies bring to many adults as they age. Crow's work suggests a need for digital literacy researchers to stay in tune with gerontological research on the physical and cognitive changes associated with aging, which come to bear on older learners' abilities to develop and engage in digital literacy practices. For instance-and germane to compositionists as well as to technical and professional communication scholars-Crow illustrates the particular conundrum of digital and new media composition for aging audiences and users. On the one hand, compositionists regularly call for digital design that is dynamic and rhetorically sophisticated; on the other hand, such designs do not automatically lend themselves to the kinds of accessibility needs shared by many older users - and users of all ages with disabilities. The seeming incommensurability of these two stances, Crow suggests, indicates a need to know more about how users, young and old, actually navigate digital texts, such that we are better able to strike a balance between overaccommodating (and thus insulting) older audiences, and underaccommodating (and thus excluding) them (91).

Extending Crow's attention to older users and producers of digital texts beyond academic contexts, Heidi McKee and Kristine Blair note that the age-based digital divide can be deeply problematic for many older people:

The digital divide based upon age is potentially just as detrimental to individuals and society as the divide based on cultural and economic resources. As more news and information, governmental business, and personal communications are conducted online, older adults who 
do not use the Internet are at an increasing disadvantage in terms of developing social relations, participating in civic discussions, and gaining valuable knowledge on issues such as health care.

While often a problem of material access, many older people are excluded from digital culture due to lack of digital literacy experience: unlike younger people who are exposed to digital technologies in school and at work, many retired older adults must rely instead on less formal support, such as community programs and centers, to fill in the knowledge gaps. McKee and Blair's essay offers, then, a call for literacy and composition scholars to identify and address the barriers many older digital literacy learners face.

Alongside consideration of the professional, physical, and social dimensions of digital literacies in the early twenty-first century, studies of older adults' technological literacy learning and practices have also prompted thinking about the ideological contexts of literacy practice and learning. Taking a critical age studies stance, my own work ("Beyond Repair") has considered the ways that literate activity is shaped by ideologies of aging. Dominant representations of technologies for older people are primarily framed in terms of health and bodily repair, with the assumption that tech appropriate for older users is inherently tech designed to compensate for physical and cognitive decline or health interventions. While many older adults do experience declining health and ability, the pervasiveness of such representations may, in fact, restrict both motivations for technological literacy learning, as well as a discourage any sense that experiences of aging could involve something other than coping with failing bodies and minds.

Just as beliefs about aging can impact literate activity, so too can literate activity be used to form and confirm beliefs about aging and age groups. Writing technologies become cultural icons of generational divides in literacy and language use, as evidenced in Brandt's The Rise of Writing. Many of Brandt's interviewees used writing habits amid technological changes as a basis for establishing intragenerational identity through intergenerational difference. Observes one interviewee, "From what I have seen my generation is the last one that still kind of reads books, still kind of wants to go for coffee and talk face to face. A shocking percentage of younger kids I see ... it's all digital" (The Rise of Writing 146). Another suggests, "I'm not as good at online research as some of the younger lawyers. They just seem to be born knowing how to do it" (147). This kind of para-literacy talk suggests that, as technological changes continue to impact literacy practices and values on a global scale, the category of aging may be more important to literacy and composition studies than ever before.

\section{Bodies and Agency}

Having primarily worked with "traditionally-abled" college students, Heidi McKee and Kristine Blair describe a particular source of surprise in working with older adults learning to use digital technologies:

The sheer physicality of computing surprised us and our bodies began experiencing computers in a new way, such as when we demonstrated and described how to sit properly at a keyboard so as to lessen bodily strain. Similarly, we held older adults' hands as they first used a mouse in order to show them how to hold and move it correctly (not in a death grip, which is exhausting, but also not too tentatively). Our failure to recognize the incredible physical dexterity (and stamina) needed to sit at and use a computer initially left us unprepared for working with older adults using computers for the first time. (23-24) 
While studies of older people should always be cautious about overdetermining the physical, biological aspects of aging, studies of older adults place particular demands on our attention to the corporeal dimensions of literacy learning and practice, and thus offer vital opportunities to investigate the role of the body in literacy and composition.

Common physical changes in later life, including reduced visual acuity, hearing loss, arthritis, and fatigue, can play a major role in literacy learning and practice (Weinstein and LaCoss 320-21). Suzy Rumsey's study of the literacies of older people in assistive and healthcare environments illustrates that, in response to the many changes brought about by old age, including physical and cognitive change, older adults must make decisions about their literacy practices. Eighty-three-year-old Sarah, for instance, found that significant changes in her health necessitated changes to her familiar literacy practices; no longer possessing the manual strength to write long-form documents, Sarah "holds on" fiercely to the practice of signing her own name, while adapting her beloved practice of reading the Bible by listening to an audio version ("Holding On" 90-91). While Rumsey's study illuminates older adults' experiences with confronting and adapting to physical changes_changes largely experienced as a reduction or total loss of previous capabilities-it also acknowledges that a loss of physical ability does not necessitate a loss of agency, since even amid changes in health, "older adults employ the same agentive decision-making process that we all do in order to use literacy" ("Holding On" 82).

This attention to agency in the context of research on the physical factors of literate activity among older adults is particularly crucial, as physical changes in old age present complications for perceptions of agency. Age studies scholars Chris Gilleard and Paul Higgs note that, as developed societies continue to age through increased affluence and longevity, the nursing home has begun to serve as an icon of an old age without agency. Gilleard and Higgs theorize that the social imaginary of the "third age," a modern period of post-working life that is defined by its lack of "agedness," depends on the imagined existence of a fourth age, which "represents not so much a particular cohort or stage of life but as a kind of terminal destination-a location stripped of the social and cultural capital that is most valued and which allows for the articulation of choice, autonomy, self-expression, and pleasure in later life" (123). Against prevalent social imaginaries that thus "treat physical and mental decline as definitive limits on agency" (Polivka and Longino 3), literacy and composition research is uniquely qualified to challenge such narrow definitions of agency.

As symbolized by the nursing home, medical contexts are especially important sites at which literacy and composition scholars might contribute to knowledge on aging, agency, and the body. Medical and healthcare contexts are fraught sites of power and agentive struggle: "[m]edicine-along with other forms of bodily knowledge-is reproduced through texts and norms," generating cultural scripts that can affect patient agency in medical contexts (Owens 18), even among younger patients. Adding old age to the complex of medical authority and the maze of health care systems can even further suppress the recognition of patient (and caregiver) agency. By pathologizing aging as a body problem, health-related materials written for elder patients often "perpetuate a narrow notion of what agency means for older adults and present limited agentive possibilities to them" (Swacha 70). Against the cultural scripts that might constrain the agency of older people on the basis of their bodily abilities and symptoms, literate activity can become an essential tool for maintaining some semblance of agentive control. For instance, as 
Yvonne Teems finds, literacy practices such as online and library research can be an essential means for older people to play a more active role in their diagnosis and treatment during interactions with medical care providers (“Seniors' Uses”).

Given the strength of connections between issues of literacy, agency, and the body afforded by studies of older populations, literacy and composition researchers familiar with disability studies are likely to find important connections. (For a discussion of the connections between aging and disability, see Teems, "My Body Feels Old,"' and in this issue.)

\section{Life-Writing and Aging}

In an archival study of personal writing pedagogy at the University of New Hampshire, Thomas Newkirk acknowledges the difference age seems to make in the context of personal writing. Asking younger college students to engage with and emulate autobiographical essays written by middle-aged writers and intended for older readers requires "young adults to impersonate older ones, to breathe, to walk, to assume body postures of men and women two, three, even four times their age" (253). Newkirk's impression that a writer's age has significant impact on written self-expression is borne out by studies of late-life personal writing at the intersections of English studies and gerontology.

The work of compositionist/gerontologist Ruth E. Ray, for example, reveals that life-story writing does more for older adults than simply pass the time in reminiscence. In Beyond Nostalgia, Ray documents older people writing life stories within several writing groups, carefully considering how the literate activity of composing and sharing a life story in a group setting participates in the social construction of identity. In observing their work, Ray notes how "social scripts" for gender, race, class, and especially age placed "rhetorical demands" on the life stories they wrote (76), such that life story writing became a practice of inscribing intersectional age identity. Ray's work with Sally Chandler further illustrates that the "interpersonal dynamics" within groups of older writers can be transformative, as participants' questions and shared reminiscence can alter "fixed and ... formulaic reminiscences", and instead "pose new meanings and create more dynamic stories that continually unfold” (46).

Literary gerontologist Kathleen Woodward's work with life-writing similarly theorizes that the life review performs important psychological and emotional memory-work: rendering the span of a lifetime as a narrative whole creates opportunities for "psychological integration" and reconciliation with conflicts of the past (2). Through an analysis of the life review writing of memory theorist Helene Deutsch, who wrote Confrontations with Myself: An Epilogue as an eighty-nine-year-old widow still grieving the loss of her husband, Woodward accounts for the purposes of writing the life review as a form of "emotional protection" amid a phase of life so marked by feelings of loss and social isolation: "the act of writing and the book itself becomes a kind of holding environment, a companion to [Deutsch]. . . Her book is, we could say, itself an instance of creating companionship; it offers an important theory of the solace of emotional memory" (5).

The "tacit tradition" of personal writing may no longer be the hot topic in composition studies that it once was (Goldblatt). However, life-writing and literacy narratives continue to serve crucial functions as sources of self-knowledge and as popular methods for studying the individual and social dimensions of literate activity. As we explore the narratives that writers construct as research participants and as students in our classrooms, writing studies might take a cue from the interdisciplinary work of Ray and Woodward 
and consider the role of age identity in life-writing.

\section{Intra- and Intergenerational Collaboration}

Composition studies has long held interest in collaboration and co-authorship, and in thinking of both literate activity and rhetorical agency as distributed rather than the work of an autonomous individual. In this regard, studies of older writers and learners have begun to emerge as important sites for investigations of writing and collaboration. Researchers and facilitators of midlife and older writers' collaborative work find that groups sometimes generate zones of proximal development (ZPD)-Lev Vygotsky's well-known concept that captures the developmental stage between what a learner knows and can do independently, and what they can accomplish with more-expert assistance-in order to "assist each others' social, emotional, and intellectual development" (Rumsey et al. 208). The middle-age and older women of Caroline Heller's writing group in San Francisco's Tenderloin district helped to fill in the developmental gaps left by underprivileged academic, economic, and social lives. Likewise, participants of W. Ross Winterowd's community writing groups served as audiences for one another, and thereby could discover new meanings for writing previously unavailable to them: writing became "a way to relive and preserve the past," to envision "a more hopeful future," and to "express their hopes, their anger, their disillusionments" (503).

While ZPD is often used to conceptualize forward-and-upward developmental progress toward more complex and independent activity in the context of learning, studies of older learners' collaborations provide an important challenge to assuming eventual independence as the sole (or even preferred) goal of collaboration. Donora Hillard's work with William, a seventy-seven-year-old man with Alzheimer's, offers a poignant example. During an eighteen-month period, Hillard worked with William as he dictated memories of his service on the USS Knapp during the Korean War. Often confused and wholly unable to physically read and write, William could still speak, but with difficulty. As Hillard worked with William to focus on the task of reminiscing about his time in the navy, she recognized that his fragmented ways of thinking and speaking required an altogether different kind of collaboration; Hillard "moved into formulating a hybrid of Knapp 'stories' pieced together from William's brief lucid recollections and existing stories from his shipmates, along with organic snippets from our conversations" (219), which she then assembled into text, adding line breaks wherever William paused in speaking. The resulting textual product of Hillard and William's collaborative authorship took something like poetic form; Hillard presents a sample, from which I excerpt here:

I'm going to go away

There's no place for me

I can't anymore

But they know me

Back from long years

I don't have anything to do

I have enough where I can look at that

And understand it (219)

William, who had been an English major and an aspiring poet in his youth, is-through his unique 
collaboration with Hillard-able to use language in a new and inventive way. While Hillard acknowledges that her framing of William's language "is always incomplete, an impossible thing," their work together signals an important shift in collaboratively composing his memories: away from narrative cohesion and fact, and toward "opening and validating the imagination" (220). As the writing work of their collaboration is reframed, so too is the language of Alzheimer's: not purely as a destructive force, but also as "a rich source of alternative creativity" (221).

Collaborations like Hillard and William's draw us outside of examining collaboration in the context of learning, and instead provide opportunities to investigate the nature of collaboration as interdependence. As frequent subjects of oral histories in literacy and composition studies and beyond, and as populations for whom language use can become quickly complicated by physical and cognitive changes, older people can, as Erin R. Anderson observed while composing her grandmother's life story, provide powerful opportunities to experience and examine the "co-constructed process of narrative composition." Through critical investigations of collaborative processes, composition and literacy studies is poised to contribute to an underexamined issue within age studies: "[ $\mathrm{t}$ ]he idea that 'dependence' may be a collaborative process" (Segal).

\section{Coming of Age: An Invitation}

The nine articles in this issue-and the subsequent "horizons of transformation" proposed by Louise Wetherbee Phelps' afterword-continue to build on and expand from these predecessors of age-aware literacy and composition research by illustrating how literate activity shapes and is shaped by experiences and ideologies of aging. Tracing the writing ecologies of two neighborhood activists in their seventies, Yvonne R. Teems consciously unites age studies and writing studies perspectives- to the benefit of both. Teems finds that "Discourses of aging" (138) and her participants' constructions of the aging experience inform and sometimes motivate their literate activity. Participants described aging as rife with risks: of becoming too sedentary, too isolated from social life, too uninformed, and too financially unstable. Against this construction of old age as a potentially dangerous time, library-based literacy practices served, for both participants, as a means to address and reduce the perceived risks-especially the risk of aging out of relevance and service to their own communities.

Both Lauren Rosenberg and Rebecca Williams Mlynarczyk turn their attentions to the "long view" of literacy development, as sparked by recent interdisciplinary exchanges about writing development through the lifespan (Bazerman et al., "Taking the Long View"; Bazerman et al., Lifespan Development). Pointing out the need for lifespan research to attend to "unconventional" pathways toward literacy development over the lifespan, Lauren Rosenberg examines the conjoined literate lives of an older couple, in which one spouse is in the midst of developing basic literacies later in life, while his spousal partner has long experienced literacy as intricately woven into her sense of self and purpose. In their partnership, the couple demonstrate how "intertwined life trajectories" prove crucial to establishing and maintaining the "desire for literacy," particularly when pathways to literacy contain many barriers (19). Also taking the long view of literacy development over the lifespan, Mlynarczyk adopts a life history approach to document the literate histories of four women, whose lifelong ways with words, both "in school and (mostly) out 
of school," (37) figured prominently in making later life vibrant and meaningful in their eighties and nineties. Literacy, for these women, continues to bring "life-enhancing" values (36).

Janet Bean, Ryan J. Dippre, and Annie Kelvie each conduct writing studies projects that challenge facets of contemporary ideologies of aging, all while offering important contributions to knowledge about literacy and composition. Exploring the seeming incongruence of faith and critical pedagogy in composition studies, Janet Bean offers a sensitive analysis of the literate activity of her mother, Janice, whom she describes as a "conservative, religious, eighty-one-year-old woman living in the rural south" (59). Rather than embodying the anti-critical stance so often assumed of older people, of faith-based communities, and of the rural south, Janice's Methodist faith leads her to engage with diverse texts that challenge her lifelong values. These critical literacy practices give rise to gradual transformations as well as entrenchments, and serve as a crucial reminder that critical literacy is "a process full of stops and starts, contradictions and dissonance" (61). Ryan J. Dippre contributes in equal measure to age studies and writing studies through the articulation of expansive agency; through sociohistoric analysis of acts of textual coordination by Frank, a retired engineer, Dippre traces the circulation of agency through Frank's textual practices and language choices from one situation to the next. In doing so, Dippre challenges assumptions that agency is inevitably reduced or lost in old age, and illustrates agency as a distributed, enacted process. While Dippre challenges limited perspectives of agency in old age, Annie Kelvie counters the "decline narrative" of aging in the US through her ethnographic study of a church reading group, whose members are predominantly older adults. Through collaborative interpretation of readings, and through the appropriation and adaptation of familiar church genres, the reading group demonstrates a form of progressive civic engagement rooted in literate activity.

Laura McGrath and Dawn S. Opel examine literacy at sites with near-opposing age-associations: for McGrath, a social media platform most often associated with the literacy practices of younger people; for Opel, a health care system that is inclined to overdetermine the role of older patients as problems. McGrath investigates the construction of age identity through her study of the social media activity of middle-aged and older women. Through surveys and case studies, McGrath illustrates the varied means by which women use technological literacies to achieve visibility within youth-obsessed culture of style and fashion circles on social media platforms. Addressing one outcome of the "crisis rhetorics" of agingthat aging populations are a burden on national resources-Dawn S. Opel contests the use of health literacy as a means of effectively pinning the difficulties and failures in navigating a complex health care system on individual patients. Simultaneously recognizing health care and literacy as distributed activity, Opel posits a model of health care that recruits patients, caregivers, providers, and even compositionists in a community care coordination effort.

Finally, Douglas Hall and Michael Harker turn us toward the pedagogical connections between age studies and literacy studies, through which compositionists might contribute to the development of age theory. Noting the potential the value of the Digital Archive of Literacy Narratives to the field, while further noting the need to examine the ways ideologies of aging inform and are revealed within the literacy narratives people tell, Hall and Harker argue for the importance of a "curriculum for aging." Toward this end, the co-authors describe an oral history project designed to help students develop understandings of literacy development that are attuned to the ideologies of aging. 
As with studies of younger people, these nine essays present varied means of examining literacy as distributed, collaborative activity, moving within ecologies and bringing communities together-or breaking them apart. In their particular focus on the literacies of older people, the authors lead us through rich sites of literate activity beyond school: private homes, places of worship, libraries, health care systems, and social media. We see literacy development over a longer lifespan, as literacies developed at different stages of life accumulate, fragment, and fade. We see older adults using literate activity to adapt to aging, as well as the physical changes of aging that necessitate adaptations to literate activity. We encounter older adults making agentive and critical choices about literacy, even among stereotypes of aging that would otherwise cast them as helpless or resistant to change. We see, too, opportunities for literacy and composition scholars, teachers, and activists to intervene in anti-aging cultural scripts.

Suzy and I have asked the authors to use terms like older adult and older people to describe the subjects and participants of their work. As age studies scholars remind us, chronological age carries fluid meaning across contexts and across the lifespan. We chose the relative term older to remind readers of that very fact. (Terms like senior citizen or retiree, which collapse the varied experiences of older people into static, homogenous groups, are consciously absent.) Suzy and I were determined that this issue would focus on literacy in relation to older people, however authors might identify such an age category, as a small step toward rectifying the general omission of older adult experiences from the field. However, in electing to refer to age studies rather than its alternative name of aging studies (or ageing studies in British English contexts), Suzy and I want to signal the sense that age, as a category of analysis, is not only relevant in the second half of life. As Leni Marshall notes, because aging is often associated specifically with older people, it is a term used to signal a specific focus on older populations; its alternative term, age studies, "recognizes aging as a continual process" (56). In this subtle way, Suzy and I acknowledge that, while the project of this special issue is to call attention to the "absent presence" of older people, in particular, it is also our hope to motivate studies of age more broadly: across the lifespan.

I urge readers to see this assemblage of work as an invitation to come of age: to recognize the absent presence of age in literacy and composition studies. We invite readers, too, to consider what remains absent, still, from the pages of this issue, and to contribute to our ever-growing list of questions for further investigation:

- What new purposes and exigencies for writing emerge at different stages of life?

- How do technological, social, and cultural changes place new demands on the existing literacies of older adults?

- How does the development of literacies or the transfer of knowledge about writing continue over a lifetime?

- How might intersectional identities of age, alongside race, ethnicity, gender, sexuality, ability, and others, constitute difference in literacy learning?

- What does it mean to age as a writer and/or as a writing teacher?

- How do we compose our late careers or post-retirement lives as compositionists?

- How well do interfaces of composing technologies account for the aging body?

- How might composition and literacy instruction participate in shaping perceptions of older people? 
- How might community literacy pedagogies foster opportunities for cross-generational composition?

- How might different cultures of aging impact literacy learning and practices?

Whether it's because we are becoming more cognizant of aging as an identity category with each passing year; whether we are increasingly conscious of loved ones and neighbors and colleagues as they grow older; whether we notice and confront ageism and generation-based conflict in personal and public spheres; whether we see age as an under-examined component of intersectional identities; whether we simply value a vision of literacy from the full span of a lifetime; or even if it is all of these things, we have reason enough to consider old age and aging as a lens through which to understand literacy and composition.

Lauren Marshall Bowen, University of Massachusetts Boston 


\section{NOTES}

${ }^{1}$ For more comprehensive introductions to the field, see Katz; Segal; Gullette, "Age Studies and Gender."

${ }^{2}$ Scapegoating is not, of course, solely applied to members of older generations. Millennials born between 1981 and 1996 have long been demonized in public discourses for ruining (or, rather, "killing") entire industries, products, social norms, and the American way of life. 


\section{WORKS CITED}

Anderson, Erin R. “The Olive Project: An Oral History Project in Multiple Modes.” Kairos 15.2 (2015): n.pag. Web. 25 July 2018.

Barton, David, and Mary Hamilton. Local Literacies: Reading and Writing in One Community. New York: Routledge, 1998. Print. https://doi.org/10.4324/9780203125106

Bateson, Mary Catherine. Composing a Further Life: The Age of Active Wisdom. 2010. New York: Vintage, 2011. Print.

---. "In Search of Active Wisdom: Libraries and Consciousness-Raising for Adulthood II." Boomers and Beyond: Reconsidering the Role of Libraries. Eds. Pauline Rothstein and Diantha Dow Schull. Chicago: American Library Association, 2010. 49-56. Print.

Bazerman, Charles, Arthur N. Applebee, Virginia W. Berninger, Deborah Brandt, Steve Graham, Jill V. Jeffery, Paul Kei Matsuda, Sandra Murphy, Deborah Wells Rowe, Mary Schleppegrell, and Kristen Campbell Wilcox, eds. The Lifespan Development of Writing. Urbana: NCTE, 2018. Print.

Bazerman, Charles, Arthur N. Applebee, Virginia W. Berninger, Deborah Brandt, Steve Graham, Paul Kei Matsuda, Sandra Murphy, Deborah Wells Rowe, and Mary Schleppegrell. "Taking the Long View on Writing Development." Research in the Teaching of English 51.3 (2017): 351-60. Print.

Beauvoir, Simone de. The Coming of Age. 1970. Trans. Patrick O’Brian. New York: Norton, 1996. Print.

Botelho, Lynn A. "The $17^{\text {th }}$ Century." A History of Old Age. Ed. Pat Thane. London: Thames \& Hudson, 2005. 113-174. Print.

Bowen, Lauren Marshall. "Beyond Repair: Literacy, Technology, and a Curriculum of Aging." College English 74.5 (2012): 437-57. Print.

---. “The Literacy Narrative of Chadwick's The First Grader." Age Culture Humanities 1 (2014): 57-87. Web. 31 July 2018.

---. "Resisting Age Bias in Digital Literacy Research." College Composition and Communication 62.4 (2011): 586-607. Print.

Brandt, Deborah. Literacy in American Lives. Cambridge: Cambridge UP, 2001. Print. https://doi. org/10.1017/cbo9780511810237

---. The Rise of Writing: Redefining Mass Literacy. Cambridge: Cambridge UP, 2014. Print. https://doi. org/10.1017/cbo9781316106372

---. "Writing Development and Life-Course Development: The Case of Working Adults." The Lifespan Development of Writing. Eds. Charles Bazerman, et al. Urbana: NCTE, 2018. 244-71. Print.

Branscum, John E., and Frank Quickert. "Portrait of a Gray Gamer: A Macro-Self Reading the Big Picture." Gaming Lives in the Twenty-First Century. New York: Palgrave Macmillan, 2007. 21728. Print. https://doi.org/10.1057/9780230601765_13

Butler, Robert N. "Living Longer, Contributing Longer." Journal of the American Medical Association(JAMA) 278.16 (1997): 1372-73. Web. 10 July 2018. http://doi.org/10.1001/jama.1997.03550160092044

Cheung, Chau-Kiu, and Alex Yui-Huen Kwan. "The Erosion of Filial Piety by Modernisation in Chinese Cities.” Ageing and Society 29.2 (2009): 179-98. Web. 1 Aug. 2018. https://doi.org/10.1017/ s0144686x08007836

Cleary, Michelle Navarre. "Anxiety and the Newly Returned Adult Student.” Teaching English in the TwoYear College 39.4 (2012): 364-76. Print.

---. "Flowing and Freestyling: Learning from Adult Students about Process Knowledge Transfer." College Composition and Communication 64.4 (2013): 661-87. Print.

Cole, Thomas R. The Journey of Life: A Cultural History of Aging in America. Cambridge: Cambridge UP, 1992. Print. 
Connors, Patricia. "Some Attitudes of Returning or Older Students of Composition." College Composition and Communication 33.3 (1982): 263-66. Web. 2 July 2018. https://doi.org/10.2307/357488

Crow, Angela. Aging Literacies: Training and Development Challenges for Faculty. New York: Hampton, 2006. Print.

---. "What's Age Got to Do with It? Teaching Older Students in Computer-Aided Classrooms." Teaching English in the Two-Year College 27.4 (2000): 400-406. Print.

Cruikshank, Margaret. Learning to Be Old: Gender, Culture, and Aging. $2^{\text {nd }}$ ed. New York: Rowman \& Littlefield, 2009. Print.

Dobrin, Sidney I. Postcomposition. Carbondale: Southern Illinois UP, 2011. Print.

Fairlie, Henry. “Talkin’ 'Bout My Generation.” The New Republic 198.13 (1988): 19-22. Print.

Federal Interagency Forum on Aging-Related Statistics. Older Americans 2016: Key Indicators of WellBeing. Web. 2 July 2018.

Frost, Alanna. "Literacy Stewardship: Dakelh Women Composing Culture." College Composition and Communication 63.1 (2011): 54-74. Print.

Gibney, Bruce Cannon. A Generation of Sociopaths: How the Baby Boomers Betrayed America. New York: Hachette Books, 2017. Print.

Gilleard, Chris, and P. Higgs. "Aging Without Agency: Theorizing the Fourth Age." Aging \& Mental Health 14.2 (2010): 121-28. Print. https://doi.org/10.1080/13607860903228762

Goldblatt, Eli. "Don't Call It Expressivism: Legacies of a 'Tacit Tradition.” College Composition and Communication 68.3 (2017): 438-65. Print.

Gullette, Margaret Morganroth. "Age Studies and Gender." Encyclopedia of Feminist Theories. Ed. Lorraine Code. New York: Routledge, 2002. 12-14. Print.

---. Aged by Culture. Chicago: U of Chicago P, 2004. Print.

---. “Creativity, Aging, Gender: A Study of their Intersections, 1910-1935." Aging and Gender in Literature: Studies in Creativity. Eds. Anne M. Wyatt-Brown and Janice Rossen. Charlottesville: UP of Virginia, 1993. 19-48. Print.

---. Declining to Decline: Cultural Combat and the Politics of the Midlife. Charlottesville: UP of Virginia, 1997. Print.

He, Wan, Daniel Goodkind, and Paul Kowal. An Aging World: 2015. Washington: US Government Publishing Office, 2016. Web. 1 July 2018. https://doi.org/10.13140/RG.2.1.1088.9362

Heath, Shirley Brice. Words at Work and Play: Three Decades in Family and Community Life. Cambridge: Cambridge UP, 2012. Print. https://doi.org/10.1017/cbo9781139046206

Heller, Caroline E. Until We Are Strong Together: Women Writers in the Tenderloin. New York: Teachers College P, 1997. Print.

Hogg, Charlotte. From the Garden Club: Rural Women Writing Community. Lincoln: U of Nebraska P, 2006. Print. https://doi.org/10.2307/j.ctt1djmhkj

Jackson, Richard, Tobias Peter, and Neil Howe. The Global Aging Preparedness Index. $2^{\text {nd }}$ ed. Washington, DC: Center for Strategic and International Studies, 2013. Web. 2 July 2018.

Journet, Debra. "Inventing Myself in Multimodality: Encouraging Senior Faculty to Use Digital Media." Computers and Composition 24.2 (2007): 107-20. Web. 10 July 2018. https://doi. org/10.1016/j.compcom.2007.03.001

Katz, Stephen. "What Is Age Studies?” Age Culture Humanities 1 (2014): 17-23. Web. 26 July 2018.

Marshall, Leni. “Teaching Ripening: Including Age When Teaching the Body." Transformations 19.2 (2008): 55-80. Print.

McKee, Heidi, and Kristine Blair. "Older Adults and Community-Based Technological Literacy Programs: Barriers \& Benefits to Learning." Community Literacy Journal 1.2 (2006): 13-39. Print.

National Center for Education Statistics. “Total Fall Enrollment in Degree-Granting Postsecondary 
Institutions, by Attendance Status, Sex, and Age: Selected Years, 1970 through 2026." Digest of Education Statistics. Apr. 2017. Web. 3 July 2018.

Newkirk, Thomas. “The Dogma of Transformation." College Composition and Communication 56.2 (2004): 251-71. Print.

Owens, Kim Hensley. Writing Childbirth: Women's Rhetorical Agency in Labor and Online. Carbondale: Southern Illinois UP, 2015. Print.

Polivka, Larry, and Charles F. Longino, Jr. "Postmodern Aging and the Future of Public Policy." Old Age and Agency. Ed. Emmanuelle Tulle. New York: Nova, 2004. 3-16. Print.

Prior, Paul, and Jody Shipka. "Chronotopic Lamination: Tracing the Contours of Literate Activity." Writing Selves, Writing Societies: Research from Activity Perspectives. Eds. Charles Bazerman and David R. Russell. Fort Collins: The WAC Clearinghouse, 2008. 180-238. Web. 1 July 2018.

Ray, Ruth E. Beyond Nostalgia: Aging and Life-Story Writing. Charlottesville: UP of Virginia, 2000. Print. Ray, Ruth E., and Sally Chandler. "A Narrative Approach to Anti-Aging." Generations 25.4 (2001): 44-48. Web. 19 July 2018.

Rumsey, Suzanne Kesler. "Heritage Literacy: Adoption, Adaptation, and Alienation of Multimodal Literacy Tools." College Composition and Communication 60.3 (2009): 573-86. Print.

---. "Holding on to Literacies: Older Adult Narratives of Literacy and Agency." Literacy in Composition Studies 6.1 (2018): 81-104. Web. 17 July 2018.

Rumsey, Suzanne Kesler, Ruth E. Ray, Lauren Marshall Bowen, and Donora Hillard. "The 'New Discourse City' of Older Writers: Aging and Disability as Assets to Collaborative Learning." ServiceLearning and Writing: Paving the Way for Literacy(ies) through Community Engagement. Ed. Isabel Baca. Leiden: Brill, 2012. 205-26. Print. https://doi.org/10.1163/9789004248472_012 Segal, Lynne. “The Coming of Age Studies.” Age Culture Humanities 1 (2013): 31-34. Web. 26 July 2018. Selfe, Cynthia L., and Gail E. Hawisher. Literate Lives in the Information Age: Narratives of Literacy from the United States. New York: Routledge, 2004. Print. https://doi.org/10.4324/9781410610768 Swacha, Kathryn Yankura. "Older Adults as Rhetorical Agents: A Rhetorical Critique of Metaphors for Aging in Public Health Discourse." Rhetoric Review 36.1 (2017): 60-72. Web. 20 July 2018. https://doi.org/10.1080/07350198.2017.1246013

Tankersley, Jim. "Baby Boomers Are What's Wrong with America's Economy." Washington Post 5 Nov. 2015. Web. 1 Aug. 2018.

Teems, Yvonne R. “'My Body Feels Old’: Seniors’ Discursive Constructions of Aging-as-Disabling.” Review of Disability Studies 12.2/3 (2016): n.pag. Web. 2 Aug. 2018.

---. “Seniors' Uses of Literacy to Gain Bodily Control in Medical Encounters." Literacy in Practice: Writing in Private, Public, and Working Lives. Eds. Patrick Thomas and Pamela Takayoshi. New York: Routledge, 2015. 46-57. Print.

Thane, Pat. “The Age of Old Age." A History of Old Age. Ed. Pat Thane. London: Thames \& Hudson, 2005. 9-30. Print.

United Nations, Department of Economic and Social Affairs, Population Division. World Population Ageing 2015. New York: United Nations, 2015. Web. 2 July 2018.

Weinstein, Gail, and Simone LaCoss. "Literacy and Older Adults." Literacy: An International Handbook. Eds. Daniel A. Wagner, Richard R. Venezky, and Brian V. Street. Boulder: Routledge, 1999. Print.

White-Farnham, Jamie. "'Revising the Menu to Fit the Budget': Grocery Lists and Other Rhetorical Heirlooms.” College English 76.3 (2014): 208-26. Print.

Winterowd, W. Ross. "2010 CCCC Exemplar Award Acceptance Speech.” College Composition and Communication 62.3 (2011): 502-503. Print.

Woodward, Kathleen M. “Telling Stories." Occasional Papers of the Doreen B. Townsend Center for the Humanities 9 (1997): 1-17. Web. 7 July 2018. 